\title{
Research on Power Grid Investment Assistant Decision Model Adapting to Power Reform Situation
}

\author{
Yidi Wan ${ }^{1,}{ }^{*}$, Wei Xie ${ }^{2}$, Haihong $\mathrm{Du}^{2}$, Wenming Pan ${ }^{2}$, Jianqing $\mathrm{Li}^{1}$, and Xiaohu Zhu ${ }^{1}$ \\ ${ }^{1}$ State Grid Anhui Economic Research Institute, Hefei, Anhui, China \\ ${ }^{2}$ State Grid Anhui Electric Power Co., Ltd, Hefei, Anhui, China
}

\begin{abstract}
. in order to thoroughly implement the new energy security strategy of "four revolutions and one cooperation", meet the requirements of power grid planning and management of energy administration, realize the strategic objectives of State Grid Corporation of China, actively respond to the severe external economic situation, alleviate the impact of policy-based price reduction, and improve the performance of internal investment management, the company needs scientific front-end decision-making, improve the efficiency of investment decision-making, scientifically determine the investment scale, structure and timing, and play a strategic leading role in investment decision-making. Through the analysis of internal and external management requirements, this paper constructs an auxiliary decision-making model of power grid investment to support the determination of investment scale, structure and time sequence, to realize the reasonable investment scale calculation of provincial companies, the calculation of investment structure of different voltage levels and the optimization of project delivery under the condition of given investment scale, which comprehensively considers the external supervision, economic development and internal management objectives, so as to assist the prior investment decision-making, improve the input-output efficiency, effectively improve the Advisory decision-making ability of investment data, and meet the company's investment decision-making needs.
\end{abstract}

\section{Research background and objectives}

Under the background of the state's continuous strengthening of investment supervision, trade frictions are superimposed on the impact of epidemic situation, and the impact of policy-based price reduction, the company's operation is facing greater pressure, and it is urgent to make scientific front-end decision-making to improve the efficiency of investment decision-making. At present, there is still room for further optimization in the company's investment decision-making: first, the investment scale decision-making lacks effective connection with the external economic situation, the company's overall business performance objectives, electricity price, etc.; the second is the lack of reasonable basis for the decision-making of voltage level investment structure; the third is the lack of scientific evaluation index system and evaluation method in the process of warehousing and warehousing.

In order to cope with the severe economic situation at home and abroad, adapt to the reform of transmission and distribution price and the investment management requirements of the national development and Reform Commission, link up the new strategic objectives of the company, promote the lean management of investment and improve the quality and efficiency of the company, on the basis of fully excavating the influence of power reform situation on the company's business, this paper constructs a power grid investment auxiliary decisionmaking model, optimizes the investment scale, structure and time sequence, and realizes the calculation of investment scale, structure and time sequence under the established target, so as to assist the prior investment decision-making and improve the input-output efficiency.

\section{Research content}

Firstly, considering the external regulatory requirements, the company's investment capacity, business needs and other factors, this paper constructs the investment scale measurement model to realize the provincial special investment scale measurement, and estimates the impact of investment on social economy and employment with the aid of investment impact quantitative measurement model; secondly, considering the current situation of power grid of different voltage levels, the investment capacity calculation model is constructed to realize the calculation of investment structure at different voltage levels; finally, the investment time series calculation model is constructed with the help of dynamic programming method to realize the optimal arrangement of project delivery sequence, so as to construct a set of optimization solutions from investment scale, structure to time sequence to support investment lean management.

\footnotetext{
* Corresponding author: 2360560755@qq.com
} 


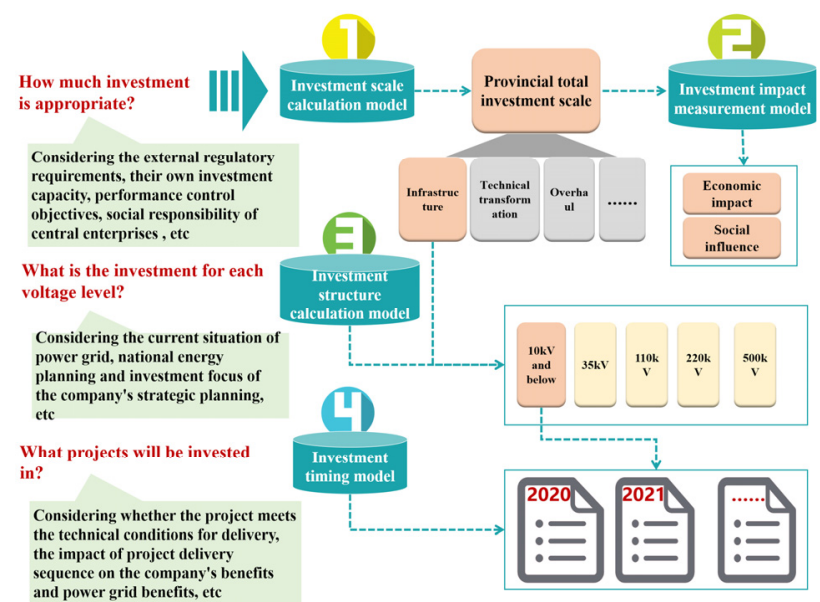

Fig. 1. Overall framework of the study.

\subsection{Combining business with finance, linking up and down, quantifying investment scale}

Fully considering the impact of the current electricity reform, by combing and analysing the linkage relationship among investment, assets, electricity price, electricity quantity, profit, etc., the company's investment capacity is quantified with the control boundary of business indicators such as total profit and asset liability ratio as constraints, so as to realize the calculation of reasonable investment scale of the company from the top-down financial perspective; starting from the scale of special reserve and historical investment scale of the company, the reasonable investment scale of bottom-up development calibre is calculated by comprehensively considering the growth of electricity, profit and other indicators, investment control performance, input-output performance, investment capacity constraints and pricing investment scale constraints; based on the theory of input-output analysis, this paper studies the pulling effect of power grid infrastructure investment on economy and upstream and downstream industries, constructs the quantitative impact measurement model of power grid investment on economy, and quantifies the pulling effect of grid investment on economic growth; based on the relationship among investment, economic growth and employment, this paper studies the pulling effect of investment on social benefits.

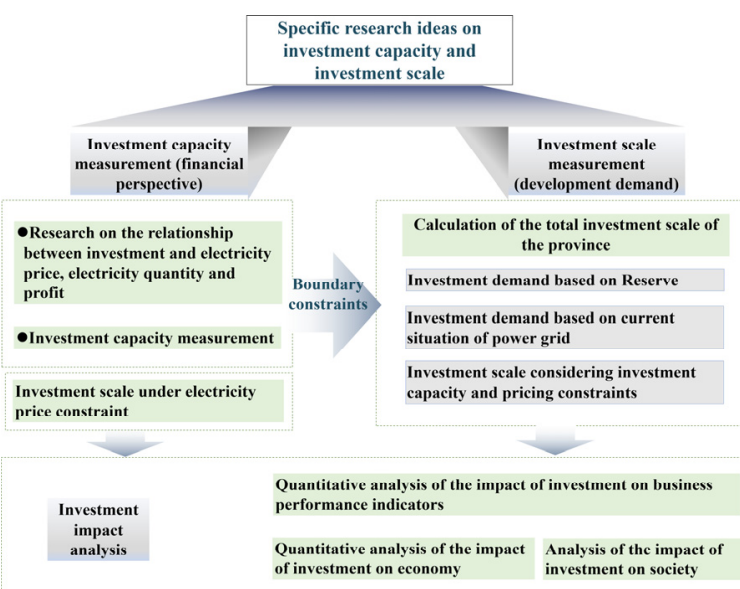

Fig. 2. Investment scale measurement framework.

\subsubsection{Measurement of investment capacity under specific benefit level}

Investment ability is affected by the company's profitability and increased debt space. When external financing is not considered, the investment capacity is the company's net profit and depreciation scale. The net profit is mainly the company's electricity sales revenue and other income scale, as well as transmission and distribution costs and other business costs. Among them, the greater impact on the company's profitability are the growth rate of electricity sales, electricity sales price, line loss rate, unit price of electricity purchase, maintenance and operation cost, etc. The external financing scale is constrained by the company's financial costs and interest-bearing debt scale control, both of which are affected by the profit drop space and the asset liability ratio can be improved. Thus, under the dual constraints of total profit and asset liability ratio, the upper limit of the company's investment scale can be calculated, that is, the company's investment capacity.

\subsubsection{Investment scale calculation based on business demand}

Combined with the company's development status, reserve scale level, historical investment change trend, input-output situation, investment plan control performance, pricing investment scale constraint and investment capacity constraint, the company's investment scale calculation is carried out.

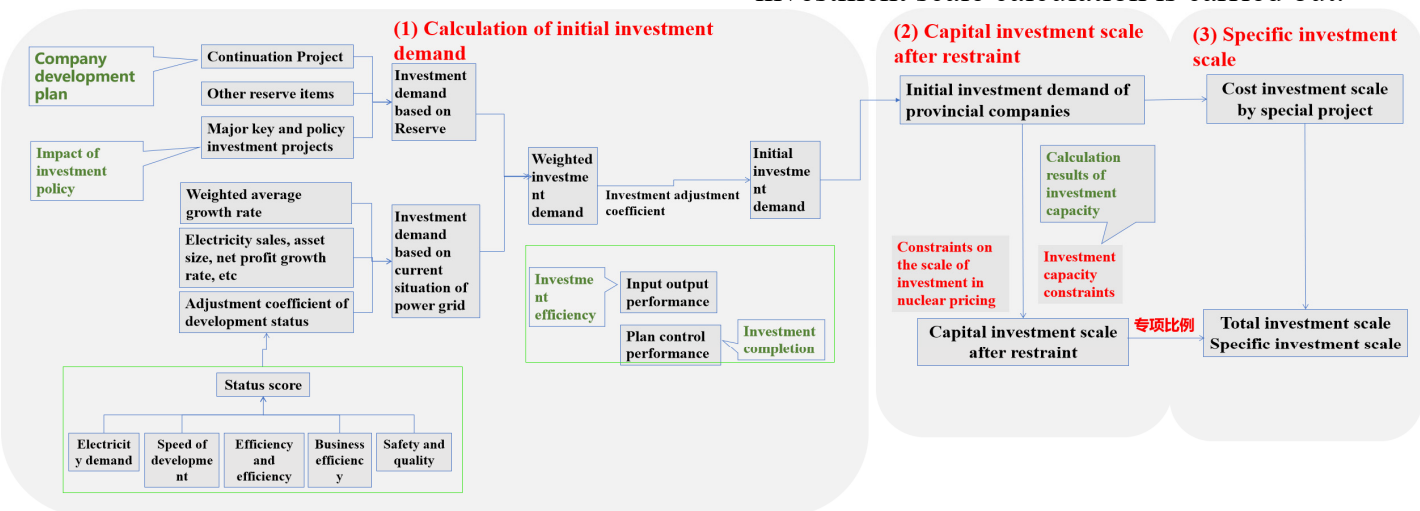

Fig. 3. Calculation ideas of investment scale. 
(1) Power grid status evaluation

From the aspects of power demand, development speed, power grid safety and quality, efficiency and efficiency, the evaluation index system of power grid status is constructed, and the differential "development status adjustment coefficient" is set based on the current situation of power grid.

(2) Calculation of initial investment demand

(1) Considering the company's development scale, investment policy, external economic situation, power grid status, investment efficiency and benefit and historical investment completion, the investment demand is determined comprehensively.

(2) Based on the reserve scale of the company, combined with the ex-warehouse rate of historical projects, the investment demand based on reserves is calculated by considering the continued construction projects, major investment in the measurement period and policy investment demand.

(3) Starting from the actual investment scale in the last period of the calculation period, considering the historical actual investment growth, external economic development and power grid development status, the investment demand based on the current situation of power grid is calculated. The initial investment demand is measured by two calibre weighted method.

(4) Considering the input-output efficiency of investment and the control effect of investment plan, the initial investment demand is adjusted to calculate the company's investment demand.

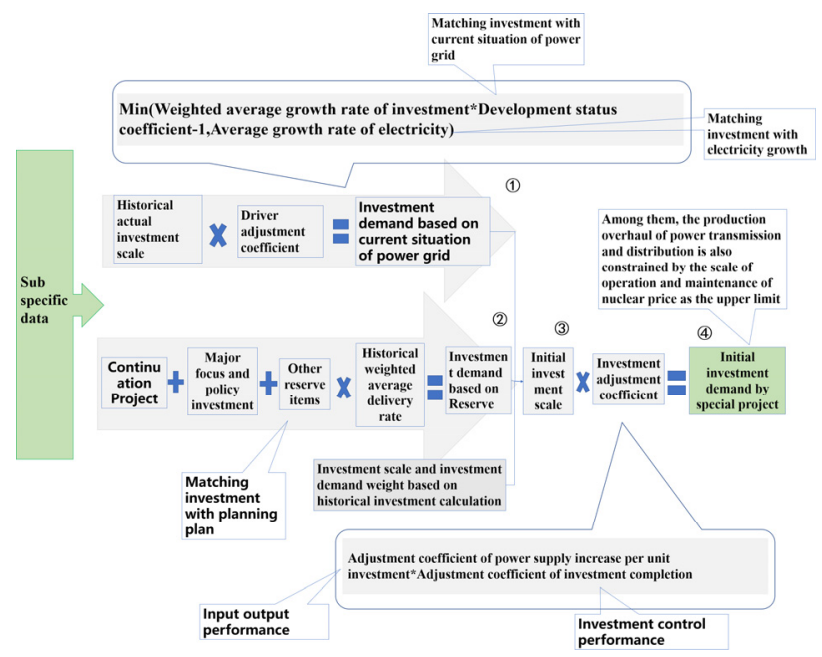

Fig. 4. Calculation steps of initial investment scale.

(3) Combined with the investment scale of the appraisal price and the investment capacity of the company, the investment scale under the constraint is calculated.

The total amount of capital special investment is constrained according to the investment capacity and the investment scale of appraisal price, and the scale of each special investment after the restriction is calculated by reducing the scale of each special project in the same proportion for the excess part.

\subsubsection{Analysis of economic and social impact of investment}

\section{(1) Economic impact}

Based on the relevant theories of macro-economy and industrial economics, this paper uses the inputoutput method to sort out the related industries of power grid investment, and studies the quantitative impact of power grid investment on the economy.

First of all, the investment direction of power grid is disassembled. According to the investment direction of power grid investment calculated by substation project and line project respectively, and based on the cost analysis of power transmission and transformation project of the company, the investment flow direction of power grid is decomposed, the investment is decomposed into various industries, and the new investment amount of each industry is determined. The construction and installation cost, equipment purchase cost and other costs used in power transformation project and line project are obtained.

Secondly, the quantitative calculation model is constructed. Based on the latest input-output table published by the National Bureau of statistics, this paper constructs a quantitative measurement model of the economic impact of investment. The input-output table is a kind of checkerboard table (matrix table) which reflects the sources and distribution directions of production input of various products. According to the total input equals to the total output, the relationship between investment and GDP added value is constructed.

Finally, data are brought in to calculate the economic impact of power grid investment. The scale of power grid investment is input into the model. The model calculates the new total output and value-added coefficient of various industries driven by grid investment, and finally outputs the GDP increment of related industries driven by grid investment. The aggregate GDP increment of all industries is the economic impact of grid investment.

(2) Social impact

The employment effect index reflects the number of employments per 10000 yuan of investment in the project construction. Based on the quantitative calculation model of the economic impact of investment, the employment contribution coefficient of each industry of power grid investment is calculated; by collecting the per capita wage level of each industry, considering the employment contribution coefficient and the per capita wage level of each industry, the pulling effect of investment in each industry on the economy is converted into the increased number of employees, and the increased employment of all industries is summarized as the social benefits of power grid investment.

\subsection{Law mining, strategic guidance, optimizing investment structure}

On the basis of determining the investment scale, a calculation model of power grid investment structure with different voltage levels based on project attribute classification is constructed to quantify the investment 
required for each voltage level to achieve the construction goal, balance the investment demand reported by each voltage level, and finally determine the investment of each voltage level.

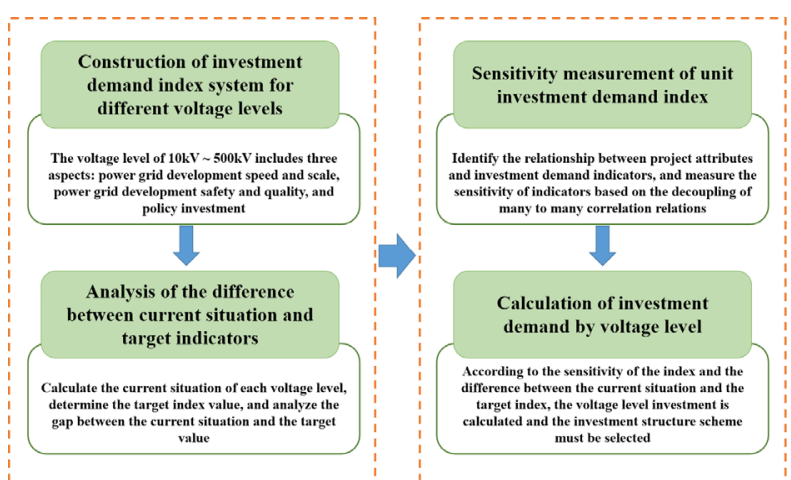

Fig. 5. Research idea of investment scale by voltage level.

\subsubsection{Linking up company strategy and constructing index system of investment demand}

Based on the principles of purposefulness, completeness, independence, operability, quantification and flexibility, and referring to the evaluation index system of power grid development level and other documents, and according to the functional orientation of power grid of various voltage levels, the investment demand index system of power grid of $10 \mathrm{kV} \sim 500 \mathrm{kV}$ with different voltage levels is established from the aspects of power grid development speed and scale, power grid development safety and quality, and policy investment.

Table 1. Investment demand index system of $220 \mathrm{kV}$ Power Grid.

\begin{tabular}{|c|c|c|}
\hline $\begin{array}{c}\text { Index } \\
\text { classification }\end{array}$ & Indicator name & Company \\
\hline \multirow{2}{*}{$\begin{array}{c}\text { Speed and } \\
\text { scale of power } \\
\text { grid } \\
\text { development }\end{array}$} & Network load & MW \\
\hline & $\begin{array}{l}\text { Capacity load ratio of main } \\
\text { transformer }\end{array}$ & l \\
\hline \multirow{8}{*}{$\begin{array}{l}\text { Safety and } \\
\text { quality of } \\
\text { power grid } \\
\text { development }\end{array}$} & $\begin{array}{l}\text { Solve the problem of } n-1 \\
\text { main transformer number }\end{array}$ & Set \\
\hline & $\begin{array}{l}\text { Solve the problem of } n-1, n- \\
1-1 \text { line number }\end{array}$ & line \\
\hline & $\begin{array}{c}\text { Solve the number of heavy } \\
\text { overload lines }\end{array}$ & line \\
\hline & $\begin{array}{l}\text { Solving the number of heavy } \\
\text { overload main transformers }\end{array}$ & Set \\
\hline & $\begin{array}{c}\text { Number of potential safety } \\
\text { hazards at level } 4 \text { and above }\end{array}$ & piece \\
\hline & $\begin{array}{c}\text { Number of electromagnetic } \\
\text { loop breaking projects }\end{array}$ & piece \\
\hline & Number of old substations & Set \\
\hline & Old conductor length & $\mathrm{km}$ \\
\hline \multirow[b]{2}{*}{$\begin{array}{l}\text { Policy } \\
\text { investment }\end{array}$} & Length of power access line & $\mathrm{km}$ \\
\hline & $\begin{array}{l}\text { Length of electric railway } \\
\text { access line }\end{array}$ & $\mathrm{km}$ \\
\hline
\end{tabular}


grid investment demand index is calculated at this time. When the total investment scale of voltage level is greater than or equal to the total investment scale of the company, the investment effect is calculated by two schemes. The first is to sort according to the importance of the indicators, relax the target value of the indicators one by one from the least important indicators, recalculate the investment of each attribute project of the power grid of each voltage level, cycle the process until the total investment of the power grid is less than the investment scale, and give the grid investment demand index at this time. The other is to calculate the investment proportion of each voltage level power grid according to the investment demand value of each voltage level, and calculate the power grid investment demand index at this time. The final investment structure is selected by comparing the investment demand index values of the two schemes.

\subsection{Highlight the benefits, plan the investment time sequence}

On the basis of determining the investment scale of each voltage level, the optimal arrangement of project delivery supporting the investment scale of each voltage level is studied. The $0-1$ dynamic programming method is used to determine the objective function and constraint conditions, and the investment time sequence delivery model is constructed to realize the optimization of project investment delivery.

\subsubsection{Build a comprehensive evaluation index system and determine the planning objective function}

Under the constraints of capital and construction resources, provincial grid companies need to sort out the construction of multiple power grid planning projects involved in the planning period. The traditional project evaluation method relies on personal experience, which is difficult to guarantee the objective rationality of the results. This study comprehensively evaluates the infrastructure projects from three aspects of reliability benefit, economic benefit and environmental benefit, which provides objective basis and reference for construction sequencing. Among them, reliability benefit is measured by power loss improvement, economic benefit is measured by power supply income, and environmental benefit is measured by carbon emission reduction benefit.

\subsubsection{The necessary conditions of project delivery are studied, and the solution constraints are determined}

Starting from the maximum investment amount, compulsory construction projects and production time, subordination and immediate relationship, mutually exclusive projects, simultaneous projects, and the number of regional investment projects, the paper constructs the constraint conditions for project delivery.

\subsubsection{0-1 dynamic programming rolling optimization to determine the optimal delivery list}

According to the principle and thought of dynamic programming, the actual needs of power grid enterprises, the objective reality and the problems encountered in the process of investment are transformed into mathematical expressions, and a dynamic programming model combining reality, availability and theory is established. Through the recursive analysis of each stage, we can make a reasonable judgment on the optimal decision of each stage. After the decision-making of each stage, we can add the corresponding state variables, decision variables and corresponding constraints to expand the corresponding state variables and carry out rolling optimization on a year-on-year scale.

\section{Conclusion}

Based on the research on the linkage relationship of key investment indicators, this study constructs the investment capacity measurement and investment scale measurement model by comprehensively considering the historical investment scale growth, investment control performance, input-output performance, reserve scale, investment capacity, pricing regulations, external macroeconomic situation and other factors, which provides a quantitative basis for determining the general control objectives of the annual comprehensive plan; the investment scale calculation model of different voltage levels and the optimal outbound model of investment projects constructed in this study will transform the empirical management into data management to support the scientific arrangement of investment plan and improve the quality of investment decision-making; the study changes the traditional investment concept of "emphasizing scale and ignoring efficiency", which effectively improves the efficiency of resource allocation.

\section{References}

1. Chen Lin. Research on investment decision method of power grid project considering differentiated development demand [D]. North China Electric Power University (2019).

2. Li Meng, Li Xiaodong. Research on investment allocation model of power grid enterprises based on investment capacity [J]. Northeast electric power technology (2016).

3. Zeng lingchi. Research on investment timing optimization of distribution network construction projects based on dynamic programming [D]. North China Electric Power University (2018).

4. Wan Jing, Zhang Wei. Economic analysis of Hubei Power Grid infrastructure projects by function [J]. Hubei electric power (2017). 